\title{
Arte, História e Educação na Psicoterapia de Grupo: em defesa da formação humana
}

\author{
Art, History and Education in Group Psychotherapy: in defense of human \\ formation
}

\section{Arte, Historia y Educación en Psicoterapia Grupal: en defensa de la formación humana}

Emanuelle da Silva Gatto Bien1; Sonia Mari Shima Barroco²

\section{RESUMO}

A pesquisa relatada tratou da elaboração de estratégia de intervenção em grupo psicoterapêutico, com atuação formativa ou educativa, subsidiada pela Psicologia Histórico-Cultural (PHC). Objetivou-se investigar contribuições da PHC para o trabalho com grupos psicoterapêuticos; assim como explorar possibilidades de se utilizar reproduções da Arte pictórica e dados históricos - tanto a contextualização histórica das obras apresentadas quanto elementos da história do Brasil e da região, considerando o processo educativo como parte da estratégia psicoterapêutica. Contou com investigações bibliográfica e de campo, sendo que esta consistiu na formação de um grupo psicoterapêutico composto por 7 mulheres em uma Unidade Básica de Saúde. Após 20 encontros, os resultados indicaram que o emprego de reproduções de obras de Arte e de dados históricos demonstrou-se eficaz como recurso disparador do processo de maior consciência: por meio delas, as participantes expuseram suas histórias de vida e seus sentidos pessoais acerca dos temas trabalhados; assim, expressaram melhorias em relação às queixas iniciais e redução do sofrimento psíquico.

Palavras-chave: Formação social do psiquismo; Psicologia Histórico-Cultural; Grupo psicoterapêutico; Arte pictórica; Saúde mental.

\begin{abstract}
The reported research dealt with the elaboration of an intervention strategy in psychotherapeutic groups, with training or educational activities, subsidized by Historical-Cultural Psychology (HCP). The objective was to investigate HCP's contributions to work with psychotherapeutic groups; as well as exploring possibilities of using reproductions of pictorial art and historical data - both the historical contextualization of the works presented and elements of the history of Brazil and the region, considering the educational process as part of the psychotherapeutic strategy. It had bibliographic and field investigations, in which consisted of the formation of a psychotherapeutic group composed of 7 women in a Basic Health Unit. After 20 meetings, the results indicated that the use of reproductions of Works of Art and historical data proved to be effective as a trigger for the process of greater awareness: through them, the participants exposed their life stories and their personal senses about
\end{abstract}

\footnotetext{
${ }^{1}$ Egressa do Programa de Pós-Graduação em Psicologia da Universidade Estadual de Maringá - UEM, Maringá/PR - Brasil; psicóloga da Prefeitura do Município de Mandaguaçu/PR - Brasil

2 UEM - Professora do Programa de Pós-Graduação em Psicologia da Universidade Estadual de Maringá, Maringá/PR - Brasil. Professora Visitante Nacional Sênior (PVNS/CAPES) do Programa de Pós-Graduação em Psicologia da Universidade Federal de Rondônia - PPGPSI/UNIR, Porto Velho/RO - Brasil.
} 
the themes worked; thus, they expressed improvements in relation to the initial complaints and reduction of psychological suffering.

Keywords: Social formation of the psyche; Cultural-Historical Psychology; Psychotherapeutic group; Pictorial art; Mental health.

\section{RESUMEN}

La investigación reportada se ocupó de la elaboración de una estrategia de intervención en grupos psicoterapéuticos, con actuación formativa o educativa, subsidiada por la Psicología Histórico-Cultural (PHC). El objetivo era investigar las contribuciones de PHC para el trabajo con grupos psicoterapéuticos; así como también explorar las posibilidades de usar reproducciones de arte pictórico y información histórica - tanto la contextualización histórica de los trabajos presentados como elementos de la historia de Brasil y la región, considerando el proceso educativo como parte de la estrategia psicoterapéutica. Tenía investigaciones bibliográficas y de campo, que consistió en formar un grupo psicoterapéutico compuesto por 7 mujeres en una Unidad Básica de Salud. Después de 20 reuniones, los resultados indicaron que el uso de reproducciones de obras de Arte y datos históricos demostró ser eficaz como desencadenante del proceso de mayor conciencia: a través de ellos, las participantes expusieron sus historias de vida y sus sentidos personales sobre los temas trabajados; así, expresaron mejoras en relación con las quejas iniciales y la reducción del sufrimiento psicológico.

Palabras clave: Formación social de la psique; Psicología Histórico-Cultural; Grupo psicoterapéutico; Arte pictórica; Salud mental.

\section{INTRODUÇÃO}

A pesquisa justifica-se ante a crescente inserção do psicólogo no campo da saúde pública e a necessidade de se pensar sua atuação profissional para além dos tradicionais atendimentos individuais, enfatizando seu trabalho educativo ou formativo. Há a necessidade de investigação acerca das contribuições da Psicologia Histórico-Cultural (PHC) para essa atuação, sob uma visão mais ampla e contextualizada de formação humana.

Isso coaduna com o exposto pelo Conselho Federal de Psicologia - CFP (2019), que sugere que o psicólogo atuante na Atenção Básica à Saúde (ABS), vinculada ao Sistema Único de Saúde (SUS) incentive e envolva-se na criação de grupos, cuja função deve ser a "[...] criação de vínculos afetivos e comunitários e apoio às situações de vulnerabilidade" (p. 62). Acrescenta que "as sessões de terapia em grupo representam a alternativa mais interessante para o SUS, na medida em que exigem poucos recursos para atender a maior quantidade de pacientes" (CFP, 2013, p. 129).

O Ministério da Saúde (BRASIL, 2013) elenca os grupos como um importante instrumento de intervenção em Saúde Mental na Atenção Básica, pois constituem uma estratégia que dialoga com a integralidade do cuidado e com o conceito ampliado de Saúde. A pluralidade dos integrantes de um grupo concede trocas de experiências, de conhecimentos e identificações que permitem transformações subjetivas que seriam inviáveis em atendimentos individuais. Os grupos na ABS representam, para seus usuários, mais um elemento da rede de apoio social e de cuidado no território de referência. Esta modalidade de atendimento carrega em si a possibilidade e a necessidade de ruptura com o modelo de atendimento normativo recorrente no serviço ofertado pelas equipes de $A B S$, em direção a uma 
perspectiva mais criativa, considerando-se as concepções teórico-metodológicas do profissional articuladas às concepções dos indivíduos, do coletivo, do território.

Sobre a aplicabilidade da psicoterapia para além dos espaços clínicos individuais, Neubern (2009) aborda a proposta psicoterapêutica pautada na PHC, conforme Gonzalez Rey, que destaca a importância e a complexidade da noção de sujeito de modo a viabilizar e preconizar que o paciente se posicione ativamente no processo terapêutico, em postura reflexiva sobre a própria produção de sentidos, em relação a si mesmo, ao terapeuta e ao processo propriamente dito. Enfrenta a ideia de psicoterapia como prática restrita ao consultório; pode ocorrer em qualquer espaço de subjetivação, uma vez que as características fundamentais da prática terapêutica são: construção de sentidos, diálogo e vínculo terapêutico. $\mathrm{O}$ autor se contrapõe à dogmatização do processo terapêutico em rituais ou espaços físicos determinados.

Elegemos, pois, como referencial teórico a PHC, com os objetivos de investigar contribuições desta vertente teórica para o trabalho com grupo psicoterapêutico; e, explorar possibilidades de se utilizar o contato com a Arte pictórica e dados históricos - tanto a contextualização histórica das obras apresentadas quanto elementos da história do Brasil e da região, considerando o processo educativo como parte da estratégia psicoterapêutica em um grupo de atendimento à saúde mental a mulheres na ABS. Buscamos as contribuições da PHC para além do âmbito educacional escolar - no qual é bem reconhecida, como atesta, por exemplo, o grande volume de publicações a respeito no Portal Periódicos Capes (www.periodico.capes.gov.br).

Compreendemos que esta proposta de trabalho psicoterapêutico apresenta uma vertente educativa, à medida que prima pela valorização da historicidade para a compreensão dos fenômenos psíquicos. Trata de um processo educativo mais amplo, visando tornar acessível a apropriação do conhecimento elaborado pela humanidade, mais especificamente da Arte pictórica e da história, a uma parcela da população que, de forma geral, possui acessos restritos a esses conhecimentos, e incidindo na compreensão que as pessoas têm de si mesmas e da sociedade. Estabelecemos interlocuções entre a Psicologia e outras áreas do saber, num estudo que se atenta ao desenvolvimento humano e às suas diferentes condicionalidades, considerando a historicidade do psiquismo e as relações sociais que direcionam a sua constituição.

A PHC explica a constituição do psiquismo pautando-se no materialismo histórico-dialético, abarcando os múltiplos condicionantes sócio-históricos que a impactam, assim como a própria história pessoal dos sujeitos singulares. Dessa forma, para o desenvolvimento da pesquisa, estudamos a constituição da singularidade das mulheres participantes à luz da historicidade da vida objetiva (MARX; ENGELS, 18451846/1998; MARTINS, 2004). A condição básica para toda a história dos seres humanos reside em sua constituição corporal, concreta, material. Sendo assim, a forma para se reconhecer e compreender determinado indivíduo, grupo ou população requer necessariamente o desvelamento das suas condições reais e concretas de produção da existência. Não que as condições externas exerçam um determinismo sobre as condições internas dos sujeitos, ambas relacionam-se de forma dinâmica e interdependente. Para Rubinshtein (1958, apud ZEIGARNIK, 1979, p. 11), "A influência externa origina um ou outro efeito psíquico apenas refratando-se através dos estados psíquicos do sujeito, através das ideias e sentimentos que nele foram formados". A PHC não considera que tudo seja formado culturalmente, mas que, sobre a base com a qual se conta no nascimento (o equipamento biológico) se constitui o edifício cultural ao longo da vida e este guarda estreita relação com os rumos e os alcances do desenvolvimento psíquico. 
Para Martins e Carvalho (2016, p. 701), "Na qualidade de produtos do desenvolvimento social da humanidade, as funções psíquicas superiores instituem-se como formas supraorgânicas de conduta, resultantes do uso de signos e do emprego de ferramentas [...]". Estes, por sua vez, sintetizam o conhecimento humano historicamente acumulado. As FPS incluem sensação, percepção, atenção, memória, linguagem, pensamento, imaginação, emoção e sentimento. As relações entre as esferas cognitiva e afetiva estão imbricadas, constituindo o psiquismo como uma unidade que sustenta a atividade humana.

Leontiev (1978) explica que o psiquismo se desenvolve em acordo com a atividade, e essa, em sua relação com as necessidades, os motivos e as emoções dos sujeitos. A necessidade consiste em um "[...] estado carencial e profundamente emocional, gerador de tensão que mobiliza a ação, havendo, do ponto de partida do desenvolvimento, um radical biológico comum às necessidades e emoções" (MARTINS; CARVALHO, 2016, p. 705). Desde o nascimento cada um apresenta necessidades vitais que, a princípio, são satisfeitas por outras pessoas. A necessidade é vivida como vazio, falta, algo indefinido e indiferenciado; ela só cria objetividade conforme se descobre o objeto que pode atendêla. A necessidade, por si só, não tem o potencial de dirigir a atividade, ela apenas precisa ser saciada. Conforme o sujeito torna-se atuante em seu meio, vai estabelecendo relações entre a necessidade e o objeto capaz de satisfazê-la, de modo que o objeto vai tomando uma valoração afetivo-positiva. Uma vez identificado, é preciso encontrar, buscar tal objeto. Essa busca redefine a relação entre sujeito e objeto, de modo que a necessidade se converte em motivo. O motivo, portanto, estimula a atividade, uma vez que abarca a unidade entre a necessidade e o objeto da mesma.

No que diz respeito especificamente à saúde mental, a Patopsicologia Experimental, desenvolvida por Bluma Zeigarnik (1901-1988) na década de 1960, constitui-se em importante referencial para os dias atuais. Zeigarnik (1979) analisa tanto os processos mentais normais quanto os alterados e afirma que nos primeiros a instância biológica é superada e incorporada pela instância cultural. Já em casos de patologia, a biológica exerce maior influência sobre a atividade mental do sujeito, ou seja, ela predomina gerando alterações na sua atividade psíquica.

No tocante à importância da Arte para o desvendamento dos sujeitos, Barroco (2007) explora a interlocução entre Psicologia e Arte, em busca de uma atuação diferenciada por parte do psicólogo. Retoma autores clássicos que abordam sobre o emprego do desenho da figura humana, sua importância como técnica, os aspectos projetivos implicados e como interpretá-los. Indaga como a Psicologia pode fazer a investigação dos homens reais, naquilo que apresentam de generalizado, compreendendo-os "[...] como produtos das múltiplas interações sociais" (BARROCO, 2007, p. 70). Em nossa pesquisa de campo, trazemos essa mesma preocupação atentando-nos a um procedimento metodológico diferenciado para a atuação do psicólogo; desta vez, na saúde pública.

Os estudos teóricos têm continuidade até o momento, mas, a pesquisa de campo que é o foco principal deste artigo ocorreu entre 2015 a 2017. Para tanto, organizamos um grupo de atenção à saúde mental para mulheres, de periodicidade semanal, em uma Unidade Básica de Saúde (UBS) localizada em um município de pequeno porte do Estado do Paraná. Partimos de duas hipóteses. A primeira é que a formação das participantes do grupo atendido como fruidoras da Arte pictórica corrobora com o desenvolvimento da consciência de si, o que possui valor psicoterapêutico. A segunda hipótese é que a apropriação ou a consciência da totalidade/universalidade promovida pela Arte redimensiona o conflito pessoal, podendo, igualmente, ter valor psicoterapêutico. Compreendemos por valor psicoterapêutico ações ou estratégias que viabilizam, por parte do indivíduo, o desenvolvimento de 
maior compreensão acerca da sua queixa inicial apresentada na UBS e, que lhes permitam vislumbrar questões para além dela (embora em intervenções psicológicas breves e focais seja de praxe se ater à problemática apresentada como queixa inicial), maior entendimento acerca do seu sofrimento psíquico e a consequente redução deste; em outros termos, a elaboração de novas estratégias de enfrentamento de tal sofrimento, num trabalho formativo ou educativo.

\section{METODOLOGIA}

A pesquisa foi aprovada pelo Comitê de Ética da Universidade Estadual de Maringá /Plataforma Brasil e pela Secretaria Municipal de Saúde do município paranaense, sendo que as participantes assinaram o Termo de Consentimento Livre e Esclarecido.

Para a formação do grupo de pesquisa, foram convidadas mulheres que se encontravam na lista de espera da UBS para atendimento psicológico em grupo. Ele foi composto por sete mulheres, cujas queixas iniciais eram: uma por enfrentamento a um câncer, duas devido ao sofrimento oriundo da viuvez, três devido às relações familiares conflituosas e uma não apresentava queixa, participou do grupo porque vinha acompanhando a mãe, que possui pouca mobilidade. Contou com a nossa coordenação (pesquisadora e psicóloga da UBS) e com o auxílio de outra psicóloga (pós-graduanda em Psicologia). Foram previstos e realizados 20 encontros, com $1 \mathrm{~h} 30 \mathrm{~m}$ de duração cada um.

Sobre a organização dos encontros, iniciaremos pelo último, visto que se diferenciou, por seu objetivo de avaliar o trabalho realizado junto ao grupo, e para tanto foi utilizada uma técnica apropriada para pesquisas qualitativas, o grupo focal (GF). Com o objetivo de gerar dados, o GF propicia debates e valoriza as interações em grupos, e é utilizado para investigações profundas sobre temas específicos (TRAD, 2009; BACKES et al, 2011). Segundo Trad (2009), o GF é de origem anglo saxônica e teve sua origem no final da década de 1940 , sendo que desde a década de 1980 constata-se um incremento significativo em seu emprego como instrumento de coleta de dados em pesquisas no campo da Saúde no Brasil. De acordo com Trad (2009), o pesquisador/moderador "[...] busca colher informações que possam proporcionar a compreensão de percepções, crenças, atitudes sobre um tema, produto ou serviços", e cabe-Ihe "[...] a criação de um ambiente favorável à discussão, que propicie aos participantes manifestar suas percepções e pontos de vista". Os participantes são estimulados a falarem sobre suas opiniões, experiências e atitudes sobre temas delimitados (SEHNEM et al, 2015).

Para os demais 19 encontros foram elaboradas sequências de reproduções de telas de pintura, utilizadas como recurso estratégico para o trabalho com o grupo. A opção pelo emprego de imagens pictóricas se deu ante ao reconhecimento da figura humana como recurso expressivo dos sujeitos que as representam ou que as fruem, uma vez que tais imagens expressam significados socialmente compartilhados e permitem a identificação e formulação de sentidos específicos (BARROCO, 2007). A organização das sequências se deu pelos eixos temáticos: família, educação, trabalho e saúde; escolhidos porque são recorrentes no trabalho de Psicologia dessa natureza, como revela a prática da pesquisadora na UBS. As reproduções das obras foram impressas em papel foto, tamanho A4. A escolha das obras se deu conforme o desenvolvimento dos encontros, de acordo com os dados que as participantes traziam das suas histórias de vida, sob o critério fundamental de serem de artistas clássicos brasileiros que retrataram figuras humanas, com posicionamento crítico às contradições da sociedade burguesa - vivenciadas cotidianamente pelas participantes. 
A cada encontro, inicialmente as reproduções das pinturas eram apresentadas às participantes e essas ficavam livres para expressarem 0 que as imagens thes suscitavam. As participantes comentavam/analisavam as obras e falavam partes de suas histórias de vida que haviam sido mobilizadas. Em seguida, eram levadas ao grupo informações sobre as obras, sua contextualização histórica, dados sobre os artistas, aspectos formais que têm sido divulgados sobre elas, e outras questões pertinentes ao eixo temático ao qual foram atreladas. Por último, as participantes eram estimuladas a estabelecerem relações entre suas histórias de vida, a história do país e do local onde viveram, com o objetivo de lhes possibilitar uma maior compreensão das suas próprias biografias, vinculando-as não somente aos fatos imediatos vivenciados e aos sentimentos a eles vinculados, mas ao contexto histórico e socioeconômico mais amplo. A cada novo encontro, recuperamos o que fora trabalhado no anterior, trabalhando a memória, a capacidade de análise e síntese, os sentimentos que vinham à tona e, desse modo, a consciência de si mesmas e do mundo. Após os encontros fazíamos uma avaliação (pesquisadora e auxiliar) e eram realizados os registros. Apenas o último encontro com o GF foi gravado em áudio.

Além de trabalharmos o sigilo com as participantes, para a manutenção do mesmo em relação às suas identidades, seus nomes foram trocados por nomes de flores, conforme suas escolhas. 0 grupo foi composto por Azaleia, Girassol, Lírio, Rosa, Violeta, Margarida e Orquídea, sendo que as duas últimas ingressaram no décimo encontro. Embora no contrato inicial combinamos que seria um grupo fechado, em dado momento uma das participantes trouxe duas vizinhas, sem nos consultar. Isso foi conversado abertamente com o grupo, retomando-se vários aspectos envolvidos. Contudo, por unanimidade, o grupo ponderou que ambas deveriam continuar (cabe destacar que isso ocorre na UBS: ante a necessidade de trabalhos formativos, e a dificuldade de adesão às atividades, não há oposição quanto ao ingresso de novos participantes dependendo da etapa do trabalho). Houve ainda uma oitava participante, Tulipa, que esteve somente em dois encontros, alegando estar muito atarefada.

De modo geral, o grupo se mostrava dinâmico; a maioria das participantes falava bastante. Todas já se conheciam seja da vizinhança, da igreja ou da participação nas atividades oferecidas pelos órgãos públicos do bairro. No Quadro 01 são esquematizadas as principais informações que caracterizam cada participante.

QUADRO 1: DADOS DAS PARTICIPANTES

\begin{tabular}{|l|c|c|c|c|c|c|}
\hline \multicolumn{1}{|c|}{ Nome } & Idade & Escolaridade & Profissão & Estado civil & Filhos & $\begin{array}{c}\text { Queixa Inicial relacionada } \\
\text { ao/à: }\end{array}$ \\
\hline Azaleia & 66 & $4^{0}$ ano & Aposentada & Casada & 3 & Câncer \\
\hline Girassol & 67 & Não teve acesso & Aposentada & Casada & 7 & $\begin{array}{c}\text { Insônia, } \\
\text { conflitos familiares }\end{array}$ \\
\hline Lírio & 58 & $4^{0}$ ano & Aposentada & Viúva & 1 & Viuvez \\
\hline Margarida & 70 & $4^{0}$ ano & Aposentada & Casada & 7 & Conflitos familiares \\
\hline Orquídea & 56 & $\begin{array}{c}\text { Ensino Médio - } \\
\text { EJA }\end{array}$ & Aposentada & Casada & 1 & Conflitos familiares \\
\hline Rosa & 64 & $2^{0}$ ano & Aposentada & Viúva & 3 & $\begin{array}{c}\text { Viuvez e cuidadora da mãe } \\
\text { idosa }\end{array}$ \\
\hline Violeta & 42 & Ensino Superior & Educadora & Casada & 0 & $\begin{array}{c}\text { Sem queixa, acompanhava a } \\
\text { mãe, que possuía pouca } \\
\text { mobilidade }\end{array}$ \\
\hline
\end{tabular}

Obs.: Não foram inseridos os dados de Tulipa. Como participou apenas de 02 encontros eles não foram computados nas análises. 
A UBS que cedeu espaço à pesquisa de campo situa-se num bairro periférico de uma cidade cuja população estimada é de cerca de 22.819 habitantes (IBGE, 2019). O bairro fica, tanto geograficamente quanto culturalmente, afastado do restante da cidade e apresenta um alto índice de criminalidade. Muitos moradores são migrantes ou filhos de migrantes advindos de outras regiões do país. Durante 0 período no qual a pesquisa empírica foi realizada, a comunidade contava com uma escola pública de Ensino Fundamental, uma UBS, uma creche e um Centro de Referência de Assistência Social - CRAS. Muitas ruas do bairro ainda não eram asfaltadas. A UBS possuía duas equipes de Programa Saúde da Família - PSF. Tradicionalmente, por volta das quatro horas da manhã os pacientes começavam a chegar e formar fila para conseguir uma consulta, dado esse que expressa como os serviços ofertados nesta UBS eram insuficientes mediante a demanda da população atendida. Uma vez apresentadas as participantes, a comunidade e a UBS, destacamos a seguir os momentos mais relevantes do processo formativo do grupo.

\section{RESULTADOS E DISCUSSÕES}

Apresentamos ao grupo reproduções de obras pictóricas, conforme o Quadro 2.

QUADRO 2: OBRAS TRABALHADAS

\begin{tabular}{|c|c|c|}
\hline Temática & Obras & Autores/Artistas \\
\hline \multirow{3}{*}{ FAMÍLIA } & Caipira Picando Fumo & Almeida Júnior (1893) \\
\hline & A Família & Tarsila do Amaral (1925a) \\
\hline & Sem Título [Casal e Criança] & Di Cavalcanti (1929) \\
\hline \multirow{2}{*}{ EDUCAÇÃO } & Leitura & Almeida Júnior (1892) \\
\hline & Moça com livro & Almeida Júnior (s.d.) \\
\hline \multirow{2}{*}{ TRABALHO } & Café & Cândido Portinari (1935) \\
\hline & Operários & Tarsila do Amaral (1933) \\
\hline \multirow{5}{*}{ SAÚDE (FÍSICA E MENTAL) } & Interior de Pobres II & Lasar Segall (1921) \\
\hline & Retirantes & Cândido Portinari (1944) \\
\hline & Baile na Roça & Cândido Portinari (1924) \\
\hline & Amigas & Cândido Portinari (1938) \\
\hline & A Feira II & Tarsila do Amaral (1925) \\
\hline
\end{tabular}

Fonte: Autoria própria

Abordaremos o trabalho com 04 obras, tendo como critério de seleção as que suscitaram discussões mais significativas para o presente artigo. A exposição seguirá a ordem na qual foram trabalhados no grupo os eixos temáticos: família, educação, trabalho e saúde. São citadas algumas participações, com 
as quais as demais mulheres se identificaram (complementando com seus relatos) ou que, de modo notório, acolheram respeitosamente.

\subsection{Família}

A obra "Caipira picando fumo", de Almeida Júnior (1893) foi a primeira reprodução apresentada ao grupo, escolhida para trabalhar a temática Família. Ponderamos ser possível utilizar não apenas pinturas que retratam pessoas compondo uma família, de fato; mas que remetessem ao convívio familiar, de forma geral, e até mesmo à atividade de trabalho, que, por sua vez, expressa e/ou determina a dinâmica das relações familiares. A escolha dessa obra, especificamente, se deu porque a maioria das participantes cresceu na zona rural, onde o fabrico e uso de fumo de corda era algo corriqueiro, ou seja, a obra trata de um contexto familiar rural e modesto sobre o qual elas já haviam relatado no primeiro encontro, ocasião na qual as participantes se apresentaram às pesquisadoras.

Com exceção da participante mais nova, reconheceram alguém muito familiar e próximo nessa obra. Falaram das figuras masculinas que faziam parte de suas vidas; contaram casos; lembraram-se de histórias e de costumes. Ao olhar a imagem, Girassol afirmou sentir-se emocionada e exclamou:

\section{- Essa aqui foi lá no fundo!}

Quando questionada sobre o porquê, contou que se lembrou de seu pai e de seu tio; de como eles produziam fumo, sentavam-se à soleira da porta para fazerem o cigarro com a palha na orelha e a faca na mão, apresentando em suas faces a tranquilidade e a canseira trazidas pelo trabalho na roça. A obra propiciou que as participantes pudessem falar de suas histórias de vida, despertou memórias de suas famílias carregadas de conteúdo emocional, o que pôde ser expresso e acolhido no contexto do grupo de pesquisa abordando as relações familiares e a própria atividade laboral dos pais. Isso demonstrou quão relevante é a obra, revelando a sensibilidade de Almeida Júnior ao representar o homem comum, o homem do povo que ajudaria a construir o Brasil republicano.

Com a reprodução de "Roda", de Dacosta (1942), as participantes rememoraram seus tempos de criança, as brincadeiras, a relação com os pais. Apontaram que meninos e meninas brincavam juntos de lenço atrás, peteca, casinha e boneca... Cantaram algumas cantigas de roda e falaram sobre como confeccionavam seus próprios brinquedos com panos, abóboras, carvões, galhos etc. Azaleia contou que as brincadeiras na infância imitavam a vida adulta. Ao pedirmos opinião sobre o encontro, Lírio disse sentir-se aliviada. Girassol afirmou que era muito bom poder contar tudo para quem gosta de ouvir. Violeta disse adorar ouvir essas histórias e Azaleia falou que se divertiu contando-as.

Na contextualização histórica de "Roda", pintada na década de 40, abordamos os problemas relativos às migrações internas e ao processo de industrialização no Brasil. Valemo-nos do que expõe Fausto (2007) sobre o decréscimo da imigração estrangeira e o aumento das migrações internas, devido à crise mundial de 1929 e a um dispositivo da Constituição de 1934 sobre quotas para a entrada de imigrantes no país que, de forma geral, não se dirigiam às cidades. Esses dados ecoam na história da família de Girassol, que veio de Minas Gerais para o Paraná trabalhar na lavoura. Contou que os que chegaram aqui encontraram uma terra fértil, que dava de tudo. Gomes (2015) aponta que o período de ocupação planejada ou colonização do Norte do Paraná teve início na segunda década do século $\mathrm{XX}$, e a facilidade para adquirir terras férteis e adequadas à cafeicultura trouxe grandes grupos para a região, tal qual a família de Girassol. 
Quando tratamos da crise de 1929, as participantes recordaram as histórias contadas por suas mães e avós. Azaleia falou sobre a falta de recursos, a fome e as condições dos imigrantes europeus; da tristeza ao ver os corpos dos falecidos, entes queridos, serem lançados ao mar, e como esse destino era inevitável. Explicou que no tempo de seus pais era comum morrer de fome. Durante a infância e a juventude das participantes a alimentação ainda era escassa, entretanto, já havia maior diversidade na alimentação, contaram elas. Isso coaduna com o exposto por Fausto (2007), ao tratar do aumento da produção agrícola destinada ao mercado interno após a década de 1930, tal qual o incremento da diversidade alimentar dos brasileiros.

Sobre o processo de industrialização no Brasil, Fausto (2007) aponta que durante a década de 1930 os produtos manufaturados importados foram progressivamente substituídos pela produção interna. A crise de 1929 e a existência de capacidade ociosa nas indústrias de base, em especial no setor têxtil, impulsionaram essa substituição paulatinamente. Mais uma vez os dados da história do Brasil foram ligados às histórias singulares das participantes: elas contaram que, quando crianças, tudo o que usavam era feito pela própria família: roupas, calçados, cobertores, utensílios domésticos, brinquedos. Depois de adultas as coisas começaram a mudar, começaram a possuir objetos industrializados, o que tornou a vida mais confortável, mais fácil - reflexo do processo de industrialização. Abordamos como as questões de ordem econômica e política no plano nacional incidem na vida cotidiana, no que usamos, vestimos, comemos, estudamos e no que sentimos.

\subsection{Educação}

No eixo temático educação os relatos marcaram a dificuldade ou impossibilidade de acesso à escola; a violência dos educadores tendo em vista a disciplina, o que as desencorajou aos estudos; e o machismo reinante, conforme o qual, saber ler e escrever, diziam os pais, era mais que suficiente às meninas. $A$ maioria falou com grande pesar da pouca ou nenhuma escolarização que receberam quando crianças e traziam em comum a percepção de que não estudaram porque seus pais não as incentivaram. Mediante os dados da história da educação no Brasil, puderam contextualizar porque, quando eram jovens, era comum estudar apenas até a quarta série, e, colocar em perspectiva suas próprias histórias escolares: vivenciaram (sem disso saberem) as tentativas de organização do sistema formal de educação brasileiro. Seus pais não tiveram acesso nenhum à escola; elas tiveram pouco acesso, e seus filhos já tiveram maior acesso, permanência e terminalidade. Em suas falas houve indicativos de que essas informações lhes trouxeram uma compreensão mais ampla e menos individualizante sobre suas próprias histórias educacionais - tidas, por elas mesmas, como de pouco sucesso.

O encontro viabilizou às participantes a contextualização e, consequentemente, a ressignificação de suas histórias de vida, pois, como aponta Barroco (2007), as histórias de vida são únicas e singulares, mas há questões próprias de cada época que têm de ser consideradas, pois são comuns a todos (ou à grande parte de uma dada classe social, ou de dado gênero). Para a autora, a importância de se considerar os aspectos históricos que contribuem para a constituição da individualidade reside no fato de que, sem essa contextualização, é atribuído aos indivíduos e às suas famílias o fardo de serem os únicos responsáveis por si mesmos, por suas conquistas e pelas dificuldades que compõem suas histórias de vida - o que não retira as responsabilidades individuais, mas pode reduzir a distância entre o idealizado e o que se pôde realizar como seres genéricos e singulares. 


\subsection{Trabalho}

Nesta temática, "Café" de Portinari (1935) merece destaque. Cinco das participantes trabalharam em lavoura de café. Encantadas com a riqueza de detalhes da obra, expuseram seus conhecimentos sobre todas as etapas da produção de café. Também contaram das mazelas desse duro ofício, os problemas de saúde advindos do esforço intenso e prolongado, sobre como a família se organizava para trabalhar na lavoura - cada filho, uma enxada! Conversaram sobre suas relações subjetivas com esse árduo serviço.

Azaleia lembrou-se da geada de 1975: sua casa era uma tapera muito rústica, velha e torta. Seu marido disse-lhe que a próxima colheita (do ano de 1975) seria boa, e eles poderiam fazer uma casa nova. Azaleia chorou muito naquele ano, pois, com a geada, além de perder a safra de café, perdeu a casa nova prometida. Ela ficou com os ombros e costas todos machucados por carregar os restos dos pés de café que tiveram de ser cortados - como na tela de Portinari, o trabalhador tem sem corpo moldado e marcado pelo trabalho. A participante relatou que, tal como ela, muita gente sofreu devido àquela geada.

Rosa contou a história da partida de seu avô, que estava doente e iria fazer um tratamento de saúde em São Paulo. No dia de sua partida, Rosa, então criança, teve de sair para ir trabalhar na lavoura de café. Ela estava no fim de uma das longas ruas da plantação e, quando viu, lá em cima, seu avô estava sendo levado numa carriola de mão para a estação na qual pegaria o trem. Não puderam parar e esperar Rosa ir despedir-se do avô sob o risco de perderem o trem. Ela subiu correndo, mas, quando chegou ao carreador, o avô já estava distante. Houve tempo apenas de trocarem acenos de mão. Aquela foi a última vez em que vira o avô, que faleceu algum tempo depois na cidade de São Paulo, onde foi se tratar. Perguntamos às participantes que sentimento esse quadro despertava nelas. Entre tantas possibilidades, disseram: saudades.

\subsection{Saúde}

"Amigas", obra de Portinari (1938), foi uma das reproduções apresentadas na temática saúde. As participantes apontaram que a forma como estão perto uma da outra indica que sejam muito próximas. Uma das participantes sugeriu que talvez estejam cochichando, contando algum segredo, parecem íntimas uma da outra. Pelos trajes, por estarem descalças e pelo morro ao fundo, consideraram que deveriam ser pobres.

Indagamos às participantes como, em suas percepções, essa obra se relacionava com a temática saúde. Margarida explicou que a saúde vai para além do corpo, que é preciso cuidar da saúde da alma. As participantes falaram da importância das amizades nos momentos difíceis da vida. Orquídea falou que os vizinhos são como parentes próximos, sempre se apoiam e se ajudam. Exemplificou sobre uma vizinha sua com quem desenvolveu uma amizade profunda; ambas se ajudam muito. Quando uma fica doente, a outra limpa sua casa, faz comida, as famílias almoçam juntas aos finais de semana. Rosa também falou de uma vizinha, amiga e confidente, que a ajuda muito. Essa vizinha cuida até mesmo da sua mãe (de Rosa) quando precisa sair de casa. Ela sabe que pode contar com sua ajuda sempre que precisa.

Falamos da importância de pensar na saúde de uma forma ampla: como prevenimos doenças e promovemos nossa própria saúde, como nos alimentamos, como empregamos nosso tempo, quais atividades fazemos, como nos relacionamos. Ademais dos condicionantes existentes na saúde - sociais, 
econômicos, culturais - em que medida podemos nos colocar como sujeitos ativos na determinação de nossa saúde física e mental, compreendendo como ambas estão necessariamente entrelaçadas. Nesse sentido, as participantes relataram como cuidam da saúde: fazendo ginástica no salão comunitário; visitando as amigas; participando de reuniões de família, de passeios, da igreja e da Pastoral da Criança; dançando; viajando. Rosa, cuidadora da mãe idosa, contou como a participação no grupo lhe ajudou a se organizar para que possa passear e visitar as amigas, cuidando, assim, de sua saúde mental.

\subsection{Conceitos da PHC e sua aplicabilidade na pesquisa de campo}

Dentre os principais constructos teóricos utilizados para embasar e conduzir a pesquisa de campo, destacamos a relação dialética "singular-particular-universal". Para Pasqualini e Martins (2015), a relação entre singularidade, particularidade e universalidade configura um princípio básico para a implementação do método materialista histórico-dialético, cujo objetivo é a apreensão dos fenômenos em sua essência concreta para além da aparência imediata. Lavoura (2018) esclarece que a singularidade do fenômeno pode ser captada em sua imediaticidade, ou seja, em sua aparência perceptível, empírica. Por meio da análise é possível abstrair elementos que se caracterizam como traços essenciais, leis gerais e universais que regem tal objeto, ou seja, a universalidade. O particular consiste no sistema de mediações que determinam as numerosas relações entre o demasiado abstrato universal e a imediaticidade concreta do singular. O autor explica e exemplifica que quando se trata da produção de objetos que atendem a necessidades - a produção material da vida social, a produção é a universalidade, uma vez que existe em toda a história da humanidade; a distribuição ocorre conforme determinadas leis sociais, correspondendo assim à particularidade; o consumo consiste na singularidade. Isso em muito importa à nossa pesquisa, pois, conforme Araújo (2014), as obras de Arte possuem um caráter generalizador e fomentam discussões sobre a totalidade, sobre os grandes problemas vividos em cada época. As reproduções de obras de Arte foram empregadas como recurso disparador para que as participantes pudessem falar justamente sobre suas singularidades e as particularidades através das quais se relacionam com a universalidade.

Os conceitos de "sentido" e "significado" também foram primordiais para estabelecermos relações entre a história do país e as histórias de vida das participantes. Através desses conceitos nos aproximamos dos sentidos pessoais atribuídos por cada participante aos eixos temáticos trabalhados, à medida que falavam sobre as situações e vivências afetivas de suas histórias de vida. Os sentidos pessoais eram aproximados dos significados sociais - historicamente elaborados - a eles atribuídos. No grupo promovemos pontes entre a história do Brasil e as histórias das participantes e suas famílias, de modo que puderam perceber como suas vivências, histórias singulares, se vinculam à história mais geral, numa relação de pertencimento. Por exemplo, o conhecimento histórico sobre o processo de industrialização permitiu que compreendessem melhor porque em sua infância e juventude confeccionavam artesanalmente os objetos dos quais faziam uso, e porque isso mudou; ficou mais fácil, como afirmaram. O contato com a história da educação no Brasil permitiu às mulheres vislumbrarem que suas histórias de dificuldades ou mesmo ausência de escolarização não eram fruto somente da falta de incentivo de seus pais, promovendo assim certa "reconciliação" com suas biografias, formando novos sentidos.

Para Luria (1986), o significado das palavras é compartilhado por todas as pessoas, enquanto o sentido consiste na separação, dentro do espectro do significado, dos aspectos ligados à situação e às vivências afetivas do indivíduo. As participantes puderam expressar e, dessa forma, tornar mais conscientes a si 
mesmas os sentidos por elas atribuídos às palavras trazidas pelos eixos temáticos que nortearam a escolha das obras.

Conforme Schlindwein (2015), a vivência estética ou fruição artística podem contribuir com os processos de tomada de consciência e com a transformação dos sentidos. Afirma que diversas FPS são mobilizadas no contato com o objeto artístico, como linguagem, pensamento, memória e sentimentos. Pontua que a Arte proporciona o desenvolvimento de sensibilidade, percepção e imaginação, permitindo a transformação de significados comungados. Vale salientarmos que Vigotski articulou a relação entre pensamento e linguagem nos estudos da consciência, o que implica o conceito de sentido. Se esse diz respeito a um fenômeno semântico particular, ele se constitui através das relações sociais, nas quais os signos ocupam papel determinante para a humanização dos sujeitos, sendo que a Arte pode ser um meio para tanto.

Souza, Dugnani e Reis (2018) salientam o potencial humanizador da Arte e suas possibilidades no sentido da elaboração de formas mais criativas, autorais e complexas de perceber e vivenciar a realidade, promovendo, a partir daí, uma alteração qualitativa das FPS. Apoiadas em Vigotski (1925/1999), as autoras afirmam que a contemplação artística é um processo ativo no qual o fruidor se esforça para ressignificar emoções e pensamentos que emergem do contato com as narrativas das obras de arte, ampliando seu repertório ao passo que experiencia algo na esfera do humano-genérico. $\mathrm{Na}$ fruição artística, as emoções podem ser vividas de forma contemplativa, e não reativa e fragmentada, configurando um terreno fértil para sua transformação e ressignificação. $O$ contato com as reproduções das obras de arte permitiu às participantes reviver e ressignificar experiências de vida, identificarem e ressignificarem sentimentos.

Martins e Carvalho (2016) reivindicam Vigotsky (2004) em sua afirmação de que "o conhecimento sobre o afeto é capaz de alterá-lo, transformando-o de um estado passivo para um estado ativo" (p. 704). Vigotski emprestou a definição de estado ativo e passivo da filosofia espinosiana (Russell, 1979): "No estado passivo o sujeito sofre a ação do objeto, refluindo sua atividade em face dele; no estado ativo o sujeito atua sobre o objeto, potencializando a atividade que incide sobre ele" (MARTINS; CARVALHO, 2016, p. 705). Essa concepção dá sustentação à ideia da Arte enquanto estratégia psicoterapêutica, uma vez que essa - técnica social do sentimento, conforme Vigotski (1999) - tem o potencial de expressar, mobilizar e expor os sentimentos; oferecendo ao indivíduo a possibilidade de um processo de reconhecimento e manipulação dos próprios sentimentos, e sua consequente transformação. Martins e Carvalho (2016) não defendem que os sentimentos devam ser reprimidos, mas regulados mediante um processo de autodomínio da conduta, que é, afinal, o "objetivo maior da formação de cada processo funcional em si e, consequentemente, do próprio sistema psíquico" (p. 709). Esse processo de controle voluntário da conduta e das funções psíquicas de acordo com finalidades conscientes é consonante com o desenvolvimento da personalidade e com o conhecimento de si mesmo e do mundo, permitindo a suplantação dos impulsos naturais em favor da adoção de finalidades e motivos colocados pela atividade social.

Garcia (2010) defende que as pinturas artísticas podem ser utilizadas como fonte documental e caracteriza esse procedimento como estudo iconográfico, abrangendo questionamentos tais quais: quem, como, quando e porque determinada imagem foi produzida. Afirma que o estudo das Artes tem se mostrado produtivo para a compreensão da cultura humana e de suas formas de representação da realidade. Devido à sua relação intrínseca com seu contexto de produção, a Arte serve como instrumento para a compreensão das relações humanas em dado contexto histórico, pois, para além 
de expressar seus produtores, revela a sociedade na qual foi produzida. Em "Café", Portinari nos deu uma demonstração inequívoca do poder da Arte de representar os homens de determinada época e as peculiaridades de seu momento histórico, com seus costumes e sua cultura. As participantes expressaram intensa identificação com a obra, que as fez rememorarem detalhes práticos e técnicos do cultivo do café, assim como suas vivências pessoais e afetivas para com a lavoura, demonstrando que essa obra cumpre, dentre tantos outros méritos, uma função documental, podendo ser utilizada como recurso para a compreensão da realidade. Essa função também pôde ser observada em relação a outras obras: "Roda" falava de uma infância da qual as mulheres compartilhavam, "Caipira picando fumo" representava com genialidade o homem comum da época, de modo que quase todas elas viram ali representadas figuras próximas, dentre outros exemplos.

\subsection{Grupo focal: a avaliação das participantes}

Sobre a avaliação e encerramento, no último encontro todas participantes compareceram e avaliaram o trabalho por meio da técnica do GF. A discussão tramitou em torno de três eixos: (1) se houve redução de sofrimento psíquico em relação à queixa inicial; (2) se a Arte se constituiu ou não em um instrumento profícuo para o trabalho formativo e psicoterapêutico; (3) se as relações entre universal/singular/particular promovidas pela contextualização das reproduções das obras de Arte contribuíram para o redimensionamento e redução do sofrimento psíquico.

No primeiro eixo constatamos que para a maioria das participantes houve redução do sofrimento psíquico em relação às queixas iniciais. As de Girassol eram conflitos familiares, afastamento dos filhos e insônia por pensar muito nos problemas da família. A participante relatou que passou a dormir melhor devido à sua participação no grupo. Disse que lhe fez bem conhecer gente, conversar e dividir os problemas. Girassol também conseguiu melhorias no relacionamento com sua família, pois compartilhar suas dificuldades com o grupo e ouvir as experiências das outras participantes a levaram a repensar seus problemas e tomar novas atitudes, desenvolvendo estratégias de enfrentamento mediante questões que Ihe traziam sofrimento psíquico. Afirmou que nos dias em que participava do grupo sua diabetes se mantinha controlada, demonstrando que, para além da melhoria diante das queixas iniciais, também conseguiu benefícios em sua saúde física. Rosa afirmou que ao final dos encontros, sentia-se melhor. Disse que poder se abrir e falar de seus problemas ajudou-a a tomar decisões. Sua queixa inicial girava em torno de não poder sair, se divertir, viver; antes porque o marido não permitia e, depois que se tornou viúva, porque é cuidadora da mãe e não recebe apoio dos irmãos. Nos últimos encontros, relatou que vinha conseguindo se organizar para visitar as amigas e fazer coisas que gosta.

Azaleia colocou seu nome na lista de espera para atendimento psicológico em grupo porque passara por um câncer e, quando o grupo da pesquisa começou, a participante já havia sido curada. Mesmo assim, avaliou que foi muito bom ter participado do grupo e que os encontros aliviavam inclusive seus sintomas físicos, suas dores. Lírio falou que passava a semana esperando chegar o dia do grupo e que achou muito bom poder relembrar seus tempos de infância. Orquídea afirmou que gostou de relembrar a própria história e também de saber que as outras participantes enfrentaram questões parecidas com as suas. Disse que lhe fez bem poder falar de seus problemas.

Nas falas acima mencionadas as participantes relataram alterações em disposições subjetivas que causavam sofrimento e mudanças concretas em suas rotinas, que servem como indicativo da ampliação de sua capacidade de se posicionarem de forma mais ativa e consciente perante a própria vida. Foram relatadas reduções de conflitos familiares, adoção de atividades que promovem saúde mental, alívio de 
sofrimentos e até mesmo melhorias de indicativos clínicos como insônia, dores crônicas e controle da diabetes. Esses resultados vão ao encontro de Rey, Goulart e Bezerra (2016) ao tratarem dos objetivos da psicoterapia. Os autores apontam que não se deve almejar unicamente a eliminação dos sintomas, "mas a preparação da pessoa para se integrar ao complexo contexto da vida cotidiana, o que está estreitamente relacionado à educação e à promoção do desenvolvimento subjetivo" (p. 57). Para os autores, é justamente esse processo que desencadeia a mudança das configurações subjetivas que provocam o sofrimento e os sintomas associados. A mudança promovida pela psicoterapia consiste na produção de novas configurações subjetivas que permitem ao sujeito vislumbrar caminhos alternativos, ante aos comportamentos já estabelecidos, geradores de mal-estar. A psicoterapia deve almejar capacitar o sujeito ao desenvolvimento subjetivo, conduzindo-o a se posicionar ativamente em sua própria vida, colocando-se como sujeito de sua existência. Para Martins e Carvalho (2016), a psicologia objetiva primordialmente contribuir para a formação e o aprimoramento dos indivíduos, assim como potencializar sua qualidade de vida e prestar-Ihes auxílio no enfrentamento a desafios existenciais.

À segunda questão todas as participantes afirmaram que o contato com as reproduções das obras de Arte [algo inusitado, que desconheciam] ajudou a rememorarem suas próprias histórias. Conforme visualizavam as reproduções das obras, e se apropriavam do contexto histórico, contavam diversos casos e histórias carregados de significados sociais e sentidos pessoais. Rosa, por exemplo, afirmou que o contato com as reproduções das obras de Arte a ajudava a se abrir. Nesse momento, cada uma mencionou a obra que mais lhe mobilizou.

Sobre o terceiro eixo, perguntamos se os dados históricos referentes às obras e aos períodos nos quais foram produzidas as ajudaram a compreender a própria biografia de uma forma diferente, a entender como suas histórias singulares fazem parte da história do país e da região, num processo formativo. As participantes disseram que sim, porém, não desenvolveram muito essa questão nesse dia. Entretanto, durante os 19 encontros apresentaram notáveis brotos de desenvolvimento nessa direção, como, por exemplo, quando as participantes ressignificaram o acesso - ou não - que tiveram à educação formal ao saberem da história da educação no país; ou quando repensaram a pobreza vivenciada em suas juventudes a partir dos dados sociais e econômicos relativos a esse período.

\section{CONSIDERAÇÕES FINAIS}

Ponderamos que a PHC forneceu subsídios para compreender e orientar o trabalho formativo ou educativo com o grupo de mulheres usuárias de ABS/UBS, indicando que o primeiro objetivo da pesquisa foi atingido, ou seja, aprofundamos nas contribuições da PHC para o trabalho com grupos psicoterapêuticos. O contato com a Arte pictórica, por meio de reproduções dela, e a abordagem dos dados históricos - tanto referentes à contextualização das obras quanto sobre a história do país e da região e a história da educação - revelaram-se um eficaz recurso disparador psicoterapêutico na intervenção em grupos de atendimento à saúde mental para mulheres na ABS/UBS. Conforme apresentávamos as reproduções das obras de Arte, as mulheres expressavam suas percepções e identificações com as pessoas, contextos e situações representadas e passavam a compartilhar suas próprias histórias. À medida que abordávamos os dados históricos, elas contextualizavam suas próprias histórias de vida e educacional e, a partir daí, podiam redimensionar crenças e sentimentos. Alcançamos, também o segundo objetivo, ou seja, investigar as possibilidades de se utilizar o contato com a Arte pictórica - ou reproduções dela - como recurso psicoterapêutico. 
Ante o processo grupal instaurado e os resultados alcançados, consideramos nossas hipóteses válidas: a formação das participantes como fruidoras de reproduções da Arte pictórica (com base na teoria vigotskiana) corrobora com o desenvolvimento da "consciência de si", possuindo valor formativo e psicoterapêutico; e a apropriação ou a consciência da totalidade/universalidade ajuda redimensionar o conflito pessoal, podendo, portanto, ter valor psicoterapêutico também. A ampliação da consciência de si pode ser didaticamente pensada em dois momentos: quando as participantes revisitam e relatam suas histórias de vida, refletindo sobre quem são e de onde vêm, e, num segundo momento, quando suas histórias singulares eram conectadas, pela pesquisadora e pela auxiliar, às particularidades e à universalidade, por meio da explanação, no grupo, de dados históricos, sociais, econômicos e políticos que servem como pano de fundo as suas existências. Ficou evidente, pelas intervenções das participantes durante nossas explanações, que esses dados as auxiliavam na compreensão das suas biografias. Houve um movimento de desculpabilização (que não se trata da negação de responsabilidades civis e éticas) das participantes por suas próprias histórias, redimensionando, assim, o sofrimento psíquico.

Estamos cientes da amplitude de tais afirmações e das condições objetivas da pesquisa de campo, e que o desenvolvimento da consciência de si e o redimensionamento dos conflitos pessoais são questões complexas e profundas, impossíveis de serem avaliadas perante o tempo e as condições de nossa pesquisa de campo. Entretanto, ponderamos que demos passos importantes nessa direção e que essas hipóteses podem servir como pontos norteadores para grupos psicoterapêuticos nos quais se reconhece a formação social do psiquismo. A pesquisa empírica pode ter continuidade, acompanhando as mulheres participantes ou propondo um novo grupo a partir do que já foi realizado. No plano teórico, pode-se aprofundar aspectos já trabalhados agregando novos conceitos pertinentes à pesquisa.

Concluímos que a metodologia que propusemos e o referencial teórico adotado para trabalhar com o grupo psicoterapêutico revelaram-se profícuos e que sua adoção e aplicação se deram em consonância com as propostas da política pública de promoção e proteção da saúde, preconizadas pelo SUS e pela ABS. Avaliamos que essa metodologia de intervenção em Psicologia é viável e assume papel educativo no âmbito da saúde - campo notadamente dominado pela perspectiva da medicalização.

\section{REFERÊNCIAS}

ALMEIDA JUNIOR, José Ferraz de. Caipira picando fumo. 1893. Óleo sobre tela, $202 \mathrm{~cm}$ x $141 \mathrm{~cm}$. Enciclopédia Itaú Cultural. São Paulo: Pinacoteca do Estado de São Paulo. Disponível em https://enciclopedia.itaucultural.org.br/obra936/caipira-picando-fumo-estudo. Acesso em 25 de junho de 2020.

ARAÚJO, Isabela de Almeida. Estudos iniciais acerca da estética lukácsiana: a dialética universal, particular e singular. Monografia, Licenciatura em Letras - Português, Departamento de Teoria Literária e Literaturas, Universidade de Brasília, Brasília, 2014. [online] Disponível em https://bdm.unb.br/bitstream/10483/9817/1/2014 IsabelaDeAlmeidaAraujo.pdf. Acesso em 25 de junho de 2020.

BARROCO, Sonia Mari Shima. Psicologia Educacional e Arte: uma leitura histórico cultural da figura humana. Maringá, PR: Eduem, 2007.

BACKES, Dirce Stein; COLOMÉ, Juliana Silveira; ERDMANN, Rolf Herdmann; LUNARDI, Valéria Lerch. Grupo focal como técnica de coleta e análise de dados em pesquisas qualitativas. O Mundo da 
Saúde. São Paulo, v. 35, n. 4, p. 438-442, 2011. [online] Disponível

em http://bvsms.saude.gov.br/bvs/artigos/grupo focal como tecnica coleta analise dados pesquis a qualitativa.pdf. Acesso em 25 de junho de 2020.

BRASIL. Ministério da Saúde. Cadernos de Atenção Básica, n. 34. Saúde Mental. Brasília:

Ministério da Saúde, 2013. [online] Disponível em

https://bvsms.saude.gov.br/bvs/publicacoes/cadernos atencao basica 34 saude mental.pdf. Acesso em 25 de junho de 2020.

CONSELHO FEDERAL DE PSICOLOGIA [CFP] (Org.) Referências técnicas para atuação de psicólogas (os) na atenção básica à saúde ( $2^{a}$ ed.). Brasília: Conselho Federal de Psicologia, Conselhos Regionais de Psicologia e Centro de Referência Técnica em Psicologia e Políticas Públicas. 2019. [online] Disponível em https://www.crp-

01.org.br/page 3796/Refer\%C3\%AAncias\%20de\%20atua\%C3\%A7\%C3\%A3o. Acesso em 25 de junho de 2020.

CONSELHO FEDERAL DE PSICOLOGIA [CFP]. Regulação dos Serviços de Saúde Mental no

Brasil: Inserção da Psicologia no Sistema Único de Saúde e na Saúde Suplementar. Brasília: CFP. 2013. [online] Disponível em https://site.cfp.org.br/publicacao/a-regulacao-dos-servicos-de-saudemental-no-brasil-insercao-da-psicologia-no-sistema-unico-de-saude-e-na-saude-suplementar/. Acesso em 25 de junho de 2020.

DACOSTA, Milton. Roda. 1942. Óleo sobre tela, 59,70 cm x 72,60. Enciclopédia Itaú Cultural. Rio de Janeiro. Museu de Arte Moderna, Coleção Gilberto Chateaubriand. Disponível em http://enciclopedia.itaucultural.org.br/obra3592/roda. Acesso em 25 de junho de 2020.

FAUSTO, Boris. História do Brasil. 12 ed., 2a reimpr.. São Paulo: Editora da Universidade de São Paulo (Coleção Didática I), 2007.

GARCIA, Débora Kelly Herculano Machado. A imagem da mulher trabalhadora retratada pela Arte comparada com o modelo de trabalho feminino apregoado pelo movimento de higiene mental. Dissertação de mestrado, Universidade Estadual de Maringá, Maringá, PR, 2010. [online] Disponível em http://repositorio.uem.br:8080/jspui/handle/1/3005 Acesso em 25 de junho de 2020.

GOMES, Valdir. Colonização no Norte do Paraná: um olhar na perspectiva da administração e do meio ambiente. Sociedade e Território, Natal, v. 27, n. 1, p. 87-100, jan/jun. 2015. [online] Disponível em https://periodicos.ufrn.br/sociedadeeterritorio/article/view/5411/5386. Acesso em 25 de junho de 2020.

INSTITUTO BRASILEIRO DE GEOGRAFIA E ESTATÍSTICA [IBGE]. Panorama Mandaguaçu. V4.3.8.18.18, 2017. [online] Disponível em https://www.ibge.gov.br/cidades-eestados/pr/mandaguacu.html. Acesso em 04 de julho de 2020.

LAVOURA, Tiago Nicola. A dialética do singular-universal-particular e o método da pedagogia histórico-crítica. Nuances: estudos sobre Educação, Presidente Prudente-SP, v. 29. n. 2, p. 4-18, 2018. [online] Disponível em

https://revista.fct.unesp.br/index.php/Nuances/article/viewFile/6044/pdf. Acesso em 25 de junho de 2020.

LEONTIEV, Alexis Nikolaevich. O desenvolvimento do psiquismo. Lisboa: Livros Horizonte, 1978. 
LURIA, Alexandr Romanovich. O desenvolvimento do significado das palavras na ontogênese. In Pensamento e linguagem: as últimas conferências de Luria. Porto Alegre: Artes Médicas, 1986. p. 43-56.

MARTINS, Lígia Márcia. A natureza histórico-social da personalidade. Cadernos CEDES, Campinas, v. 24, n. 62, p. 82-99, abril. 2004. [online] Disponível

em https://www.scielo.br/scielo.php?script=sci arttext\&pid=S0101-

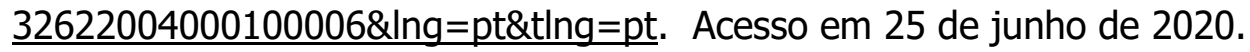

MARTINS, Lígia Marcia; CARVALHO, Bruna. A atividade humana como unidade afetivo-cognitiva: um enfoque histórico-cultural. Psicologia Em Estudo, Maringá, v. 21, n. 4, p. 699-710, out./dez, 2016. [online] Disponível em https://doi.org/10.4025/psicolestud.v21i4.32431. Acesso em 25 de junho de 2020.

MARX, Karl; ENGELS, Friedrich. A ideologia alemã. 2. ed. São Paulo: Martins Fontes, 1998. (Trabalho original publicado em 1845-1846)

NEUBERN, Maurício da Silva. Resenha: Psicoterapia, Subjetividade e Pós-Modernidade. Uma aproximação Histórico-Cultural. Psicologia: Reflexão e Crítica, Porto Alegre, v. 22, n. 2, p. 312314, 2009. [online] Disponível em https://dx.doi.org/10.1590/S0102-79722009000200019. Acesso em 01 de julho de 2020.

PASQUALINI, Juliana Campregher; MARTINS, Lígia Marcia. Dialética singular-particular-universal: implicações do método materialista dialético para a psicologia. Psicologia \& Sociedade, São PauloSP, v. 27, n. 2, p. 362-371, 2015. [online] Disponível em http://www.scielo.br/scielo.php?pid=S0102$\underline{71822015000200362 \& s c r i p t=s c i}$ abstract\&tlng=pt. Acesso em 25 de junho de 2020.

PORTINARI, Cândido. Café. 1935. Óleo sobre tela, $130 \mathrm{~cm}$ x $195 \mathrm{~cm}$. Vírus da arte \& Cia. Rio de Janeiro. Acervo do Museu Nacional de Belas Artes. Disponível em http://virusdaarte.net/portinaricafel. Acesso em 25 de junho de 2020.

PORTINARI, Cândido. Amigas. 1938. Óleo sobre tela, $70 \mathrm{~cm}$ x $60 \mathrm{~cm}$. Lilian Pacce. Disponível em https://www.lilianpacce.com.br/e-mais/exposicao-candido-portinari-sao-paulo-galeria-almeida-dale/. Acesso em 25 de junho de 2020.

REY, Fernando González; GOULART, Daniel Magalhães; BEZERRA, Marília dos Santos. Ação profissional e subjetividade: para além do conceito de intervenção profissional na psicologia.

Educação, Porto Alegre, v. 39, n. esp. (supl.), s54-s65, dez. 2016. [online] Disponível em http://revistaseletronicas.pucrs.br/ojs/index.php/faced/article/view/24379. Acesso em 25 de junho de 2020.

SEHNEM, Gabriela Dutra; ALVES, Camila Neumaier; WILHELM, Laís Antunes; RESSEL, Lúcia Beatriz. Utilização do grupo focal como técnica de coleta de dados em pesquisas: relato de experiência.

Ciência, Cuidado E Saúde, v. 14, n. 2, p. 1194-1200, abr./jun. 2015. [online] Disponível em http://periodicos.uem.br/ojs/index.php/CiencCuidSaude/article/view/21960. Acesso em 25 de junho de 2020.

SCHLINDWEIN, Luciane Maria. As marcas da arte e da imaginação para uma formação humana sensível. Cad. Cedes, Campinas, v. 35. n. Especial, p. 419-433, out. 2015. [online] Disponível em https://www.scielo.br/pdf/ccedes/v35nspe/1678-7110-ccedes-35-spe-00419.pdf. Acesso em 25 de junho de 2020. 
SOUZA, Vera Lúcia Trevisan; DUGNANI, Lilian Aparecida Cruz; REIS, Elaine de Cássia Gonçalves dos. Psicologia da Arte: fundamentos e práticas para uma ação transformadora. Estudos de Psicologia, Campinas, v. 35, n. 4, p. 375-388, 2018. [online] Disponível em http://dx.doi.org/10.1590/1982$\underline{02752018000400005}$. Acesso em 25 de junho de 2020.

TRAD, Leny A. Bomfim. Grupos focais: conceitos, procedimentos e reflexões baseadas em experiências com o uso da técnica em pesquisas de saúde. Physis: Revista de Saúde Coletiva, Rio de Janeiro, v. 19, n. 3, p. 777-796. 2009. [online] Disponível em https://doi.org/10.1590/S010373312009000300013. Acesso em 25 de junho de 2020.

VIGOTSKI, Lev Semynovich. Psicologia da Arte. São Paulo: Martins Fontes, 1999.

VIGOTSKY, L. S. Teoría de las emociones: estudio histórico-psicológico. Madrid, España: Akal, 2004.

ZEIGARNIK, Bluma V. Introducción a la Patopsicologia. La Habana: Científico Técnica, 1979. 